\title{
Analgesic effects of dexamethasone when given perineuraly or intravenously in the upper arm bone fracture and shoulder joint surgery
}

\author{
Iveta Golubovska ${ }^{1}$, Aleksejs Miscuks ${ }^{1,2}$, Jelena Kucina ${ }^{1}$ \\ ${ }^{1}$ Hospital of Traumatology and Orthopaedics, Anaesthesia and Intensive care unit, Riga, Latvia. \\ 2 University of Latvia, Anaesthesiology and Intensive Care, Riga, Latvia.
}

\section{Background and Aims:}

Shoulder surgery is associated with severe post-operative pain. Pain delays early rehabilitation, increases morbidity and lowers quality of life.

In an effort to improve analgesia and faciliate mobilization, regional anaesthesia in the form of an interscalene aproach to the brachial plexus is often used (Fig.1.).

Finding pharmacologic adjuvants to the local anesthetic that could reliably prolong the analgesia effect has been the focus of researchers recently.

Aim of the work was to investigate which of administration methods: dexamethasone perineuraly or intravenously prevents pain more effectively and improves patient quality of life.

\section{Methods:}

Prospective, randomized study conducted at Hospital of Traumatology and Orthopaedics after Ethics committee approval. Study involved 75 patients with upper limb fracture or shoulder joint surgery in RA and GA.

Group I: Bupivacaine 0.25\% - 70mg + Dexamethasone 8mg perineuraly.

Group II: Bupivacaine $0.25 \%$ - $70 \mathrm{mg}$ perineuraly + Dexamethasone 8mg i/v.

Group 0 (control): Bupivacaine $0.25 \%$ - $70 \mathrm{mg}$ perineuraly.

Stimulator and ultrasonography were used for nerve identification.

Following indicators were fixed: pain intensity, morphine consumption, patient satisfaction. Statistical analysis was

\section{Results:}

All groups were comparable in age, sex, ASA status, body mass, types of surgical procedure and duration of surgery. The were no statistically significant differences between groups ( $p>0.05)$.

The mean morphine consumption for the control group on D0 was significantly higher - $26.4 \mathrm{mg}$, for group I $-15.6 \mathrm{mg}$ and $13.2 \mathrm{mg}$ for group II $(p<0.05)$, (Table 1$)$.

Table 1. The mean oral morphine consumption $(\mathrm{mg})$ at $\mathrm{DO}$ and POD1.

\begin{tabular}{|l|c|c|c|c|}
\hline & Group 0 & Group I & Group II & P value \\
\hline $\begin{array}{l}\text { Mean opioid dose } \\
\text { at DO }\end{array}$ & 26.4 & 15.6 & 13.2 & 0.016 \\
\hline $\begin{array}{l}\text { Mean opioid dose } \\
\text { at POD1 }\end{array}$ & 21.8 & 16.8 & 12.4 & 0.057 \\
\hline
\end{tabular}

D0 - operation day; POD1 - first posoperative day

The groupe 0 has tendency to have the highest morphine consumption also at POD1 $(p=0.057)$.

Pain reliably $(p<0.05)$ differed on D0 at all standardized times (Table 2; Fig.2.). Pain was significantly lower in I and II groups comparing to the control group (group 0). There was significant difference in pain intensity between groups I and II in favor of the intravenous group $(p<0.05)$.

References: performed using SPSS software.

Table 2. Visual analogue scale (VAS) pain scores for groups on D0 (standartized times).

\begin{tabular}{|c|c|c|c|c|}
\hline & Group 0 & Group I & Group II & P value \\
\hline $\begin{array}{c}\text { Maximum VAS } \\
\text { at first 24 h }\end{array}$ & 7.0 & 4.9 & 3.8 & 0.0001 \\
\hline $\begin{array}{c}\text { 2 h after } \\
\text { operation }\end{array}$ & $3.6 \pm 3.2$ & $1.6 \pm 1.9$ & $0.2 \pm 0.4$ & 0.0001 \\
\hline $\begin{array}{c}\text { 6 h after } \\
\text { operation }\end{array}$ & $4.1 \pm 2.6$ & $1.5 \pm 1.6$ & $0.2 \pm 0.5$ & 0.0001 \\
\hline $\begin{array}{c}\text { 12 h after } \\
\text { operation }\end{array}$ & $4.8 \pm 2.4$ & $2.2 \pm 2.0$ & $1.0 \pm 1.2$ & 0.0001 \\
\hline $\begin{array}{c}\text { 24 h after } \\
\text { operation }\end{array}$ & $4.4 \pm 2.0$ & $2.6 \pm 1.8$ & $2.0 \pm 1.4$ & 0.0001 \\
\hline $\begin{array}{c}\text { Mean VAS at } \\
\text { first 24h }\end{array}$ & $6.2 \pm 1.9$ & $4.3 \pm 1.4$ & $3.4 \pm 0.9$ & 0.0001 \\
\hline
\end{tabular}

Values are expressed as mean \pm SD.

Figure 2. Visual analogue scale (VAS) pain scores for groups on D0 (standartized times).

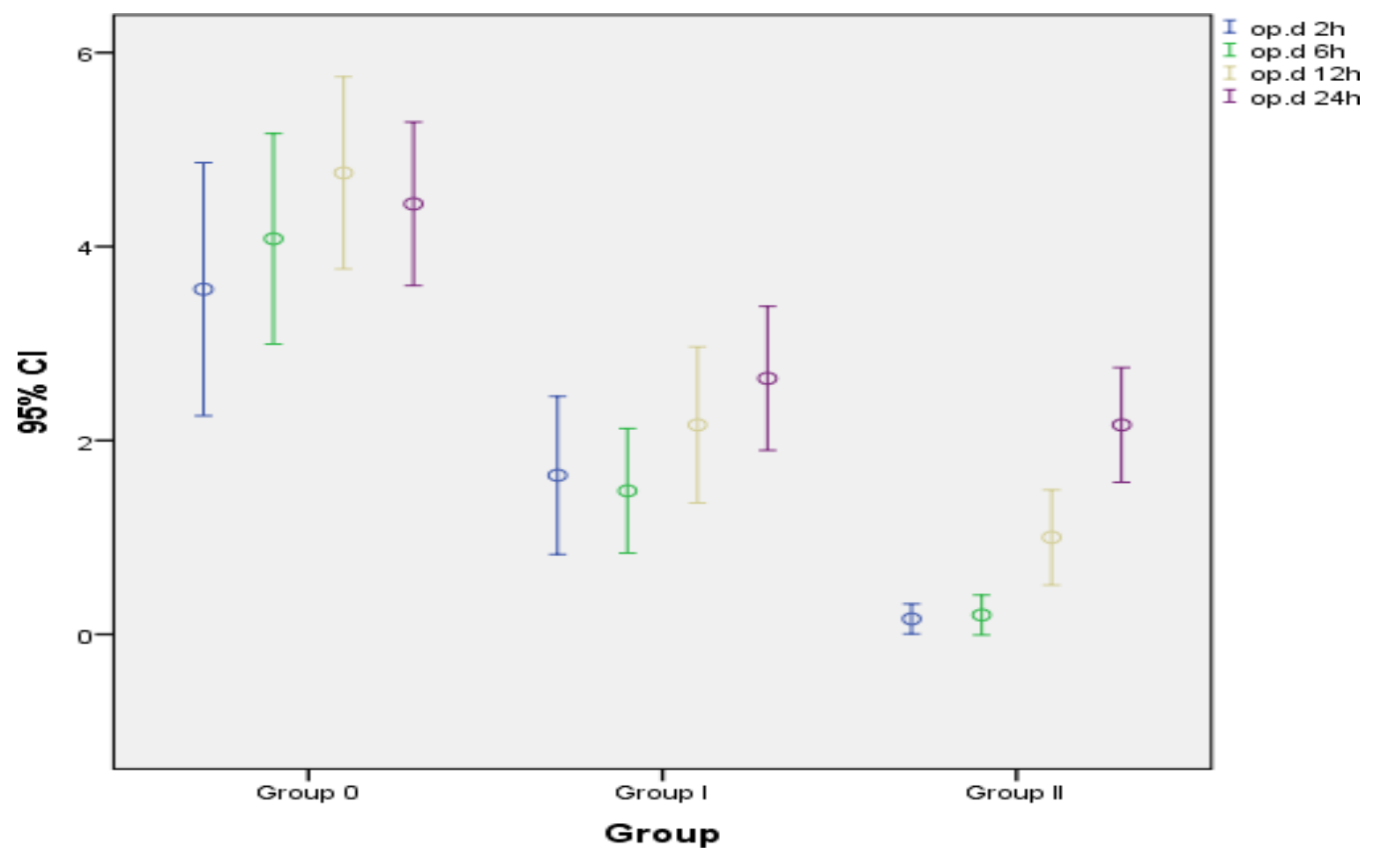

Satisfaction with analgesic method was $3.6 \pm 0.5$ in group I, $3.3 \pm 1.5$ in group II and $2.9 \pm 0.7$ in group 0 on $\mathrm{D} 0(\mathrm{p}=0.014)$.

In the control group, at first night, sleep disorders were more frequent $(72.0 \%)$, but in group I only $12.0 \%$ and $4 \%$ in group II $(\mathrm{p}<0.05)$.

\section{Conclusion}

The pain intensity is significantly lower in the dexamethasone groups, especially if systemically given. Opioid consumption is significantly lower in dexamethasone groups and patient postoperative period quality is significantly higher in dexamethasone groups.

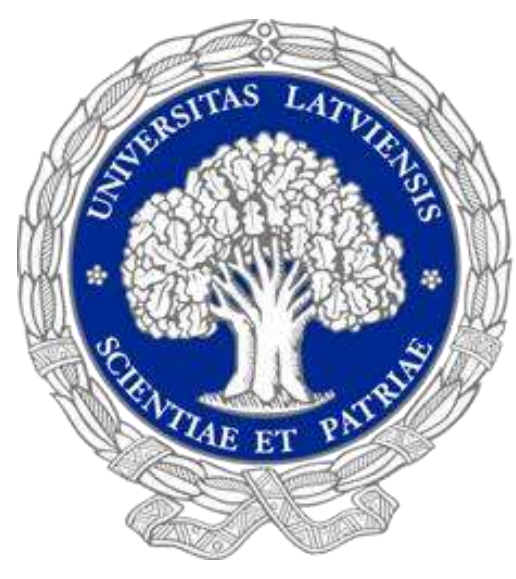

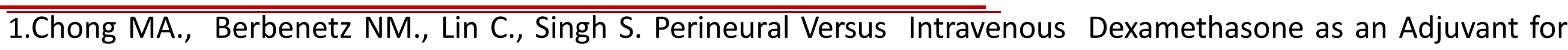
Peripheral Nerve Blocks: A Systematic Review and Meta-Analysis. Reg Anesth Pain Med, 2017;42(3):319-326.

2.Rosenfeld D.M., Ivancic M.G., Hattrup S. J. et al. Perineural versus intravenous dexamethasone as adjuncts to local anaesthetic brachial plexus block for shoulder surgery. Anaesthesia 2016, 71, 380-388.

3.Zhao WL., Ou XF., Liu J.et al. Perineural versus intravenous dexamethasone as an adjuvant in regional anesthesia: a systematic review and meta-analysis. J Pain Res, 2017 Jul 4;10:1529-1543.

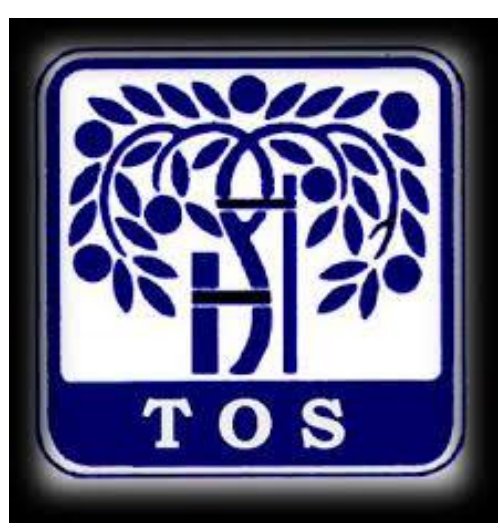

